\title{
ANNOTATION
}

\section{The Ophthalmic Benefit and Sight-Testing Opticians}

In the oft quoted saying, "the exception proves the rule," the word prove has the same meaning as in the parable in which a man excused himself from attending a great supper because he had bought five yoke of oxen and must go to prove them, that is to test them, so an exception tests a rule.

As a rule medical men who have experience of eye disease regard the practice of sight-testing opticians as fraught with danger. Adrian Caddy, M.D., F.R.C.S., is, however, not in agreement with this rule, and his views, which he has expressed in an outspoken letter to The Lancet, afford a test as to its validity.

Dealing with the subject of the administration of ophthalmic benefit he says, "that in the majority of cases the services of an ophthalmic surgeon are unnecessary and that an optician can do all that is needful;" also that he thinks " the real damage that can be done to the eyes by unrestricted prescribing by opticians is extremely slight, practically the only risk being that a case of rise of tension in the eye from whatever cause might go undetected."

It will be well here to contrast these exceptional views of $\mathrm{Mr}$. Caddy's with some extracts from the considered Report of the Council of British Ophthalmologists on "Sight-testing by Opticians," published in this Journal in December, 1922. It says :-

"The treatment of headaches, associated with errors of refraction demands not only the use of glasses, but also constitutional treatment, which can only be determined by a medical man. In some cases of defects of the muscular balance of the eyes, the use of prisms is necessary. The correct estimation of these and a complete investigation of the case are most difficult problems, since some of these muscular defects are among the earliest signs of serious diseases of the nervous system.

"Changes in the refraction of the eyes are often produced in the early stage of eye disease. For example, myopia (short sight) often appears in the early stages of cataract, or of chronic glaucoma, a disease which untreated inevitably leads to blindness. Hypermetropia (long-sight) may be met with in the early stages of a malignant tumour. In such cases glasses may bring visual acuity up to a normal standard, but an optician will fail to recognize the disease which will thus be left to run its course.

"Optical defects and disease constantly overlap; the former cannot be differentiated with certainty from the latter, nor the latter definitely excluded by any but a medical practitioner who has had special training and experience." 
Mr. Caddy suggests that a patient requiring "ophthalmic benefit" should in the first place be sent by his panel practitioner to an optician, and that only those cases in which the optician is unable to obtain normal vision with glasses should be sent on to an ophthalmic surgeon. It is, however, stated in the Council of British Ophthalmologists' report, that "disease very serious to the eye, or threatening even life, may occur in an eye with perfect acuity of central vision."

Mr. Caddy criticises the way in which the "ophthalmic panel" has been constituted. He says "The ophthalmic panel consists of a list of names and addresses of doctors and nothing more." Apparently he is unaware of the conditions which are required before a practitioner can have his name entered on this panel, and which were drawn up by a joint committee of the Council of British Ophthalmologists and the British Medical Association. They are published in Vol. VIII, p. 591 of this Journal.

We regret to hear that the British Medical Association is showing some reluctance to the reconstitution of this joint committee which did such useful work while it lasted. Combined action by all those interested would be particularly useful just now in connection with a Bill which has been printed and may shortly come before Parliament, entitled the "Optical Practitioners (Registration)." This Bill in its preamble states that it is designed to "secure the registration of optical practitioners and to regulate the practice of sight-testing, and for purposes incidental thereto."

One of its clauses lays down that, "Any registered practitioner shall be entitled to practice optometry, and to give certificates relating to visual acuity or visual defects, which shall be recognised as admissible by any local or central authority or government department in any part of Great Britain." "Optometry" it defines as "the practice of optometry, refraction, or sight-testing, or the examination of the human eye for the purpose of ascertaining any departure from the normal state of vision, measuring its functional powers and adapting or prescribing mechanical means for the aid thereof."

If this bill became law it would mean that Government departments and other public bodies would have to accept from advertising opticians whose business it is to sell spectacles, and who have received no medical training, certificates as to the presence or absence of eye disease. To such a proposal it is suggested that the General Medical Council should give its sanction by appointing one of its members to represent it on the "Optical Practitioners Board of Control."

The Minister of Health has appointed a Departmental Committee to consider the Bill, the members of which are as follow: Mr. F. B. Merriman, O.B.E., K.C., M.P. (chairman) ; Mr. O. Aves; 
Mr. W. B. Barker ; Mr. H. B. Brackenbury, M.R.C.S.; Mr. L. G. Brock, C.B.; Mr. E. Treacher Collins, F.R.C.S.; Mrs. W. L.Courtney, O.B.E.; Lord Cozens-Hardy; Mr. R. J. Davies, M.P.; Mr. H. L. F. Fraser, M.A., LL.B.; Dr. C. O. Hawthorne, M.D., F.R.C.P.; Mr. G. E. Houghton, and Sir Henry Keith.

\section{ABSTRACTS}

\section{I.-GLAUCOMA}

(1) Derby, Dr. G. S., Waite, Dr. J. H., and Kirk, E. B. (Boston). - The light sense in early glaucoma, particularly the achromatoscopic threshold at the macula. Trans. Ophthal. Soc. U.K., Vol. XLV, Pt. i, 1925.

(1) Derby, Waite, and Kirk in this paper describe their methods and apparatus for accurate and delicate testing of the light minimum and difference sense. For details of these the original, which is adequately illustrated, must be consulted. The authors begin by plotting out graphs under the standard conditions for 100 normal eyes, discussing the nature of the curves obtained, and comparing them with those obtained from glaucoma patients and from glaucoma suspects. Their conclusions are as follows :

"1. Opposed to the beliefs expressed in the standard texts, we believe with Hecht that, properly measured in the normal eye, dark adaptation proceeds at a precipitous rate for several minutes after the onset of darkness, and that it reaches almost its maximum in ten minutes.

2. For uniformity of results we believe that pre-exposure of the tested eye for five to ten minutes to a known intensity of light is a necessary procedure.

3. We believe that standardization of the pupil is a sine qua non for an accurate study of the light-sense, and we offer pilocarpine fixation as the method of choice over all other methods.

4. With the low intensities at which we worked we have been unable to find any significant alterations in the light difference (L.D.) in glaucoma, either in early or established glaucoma.

5. In established glaucoma, light minimum (L.M.) is regularly altered in two ways: first the rate of dark adaptation is retarded, and second the ultimate L.M. is raised.

6. In glaucoma suspects before there is any clinical evidence of the disease, our results show an abnormal alteration in the light minimum, manifested as a retarded adaptation rate, and as an increased ultimate threshold. In brief our results suggest that the light sense in early glaucoma is affected before there is any sustained 